\title{
Environmental Management Strategies Elucidated by Case Studies and Linkage with Pollution Prevention Hierarchy
}

\begin{abstract}
Hamere Yohannes*
*Center for Environmental Science, College of Natural Sciences, Addis Abeba University, Ethiopia

Abstract: This paper emphasize on intensive desk review by using data from research articles, books, reports and different documents to explore best case studies for different environmental management strategies and observe the link of these strategies with pollution prevention hierarchy. Environmental management evolves through a serious of strategies starting from passive to reactive and to proactive since 1960s. In passive approach, there was defensive mechanism and no significant management of the environment. In reactive approach, mainly end of pipe system was used to reduce the environmental pollution. Proactive approach is recent evolution focus on environment pollution prevention trough cleaner production. In really situation these all strategies could happen in current time as evidences from different case studies. Passive approach could directly link with the last option of pollution preventionhierarchy which is disposal. Though, Cleaner production and pollution prevention share similar principles, Pollution prevention holds broader concept than cleaner production since it considers the whole environmental pollution prevention rather than only focusing on production /manufacturing process like cleaner production.
\end{abstract}

Keywords: end of pipe, cleaner production, Passive approach, pollution prevention hierarchy

\section{INTRODUCTION}

There was virtually no corporate environmental management prior to the 1960s. Early industrializing societies were so occupied with increased production that the environmental damage associated with economic growth was virtually ignored. The absence of environmental legislation enabled firms to operate without any environmental safeguards, and the ensuing pollution created a wide range of ecological problems. The publication of Rachel Carson's Silent Spring (1962), however, heralded the arriva1 of the environmental era, helping to initiate a major shift in societal perception about the environment. After this, many environmental legislation, policy, act and strategy were arise (Hilson, 2000a).

Environmental management has evolved over the years through a series of successive paradigms: (a) Passive environmental management; (b) Reactive environmental management or end-of-pipe approaches; (c) Proactive environmental management or cleaner production (Hilson, 2003). Passive environmental management is defensive. In this strategy any system that exists namely and requires minimum maintenance can be used (Robb and Robinson, 1995). Reactive environmental strategy is compliance strategy, wherein firms rely on pollution reduction through an "end-of-pipe" approach, often resisting the enactment and enforcement of environmental legislation (Hart, 1995). In recent years, sustainable industries determined that conventional end-of-pipe environmental systems are not effective at damage remediation and are costly to operate and maintain (Hilson, 2000b). It was concluded that the solution to these problems is to replace the conventional end-of-pipe equipment with cleaner technologies (i.e. equipment that emits little or no hazardous material or that tackles pollution at the source rather than after it is discharged) and to implement cleaner production practices as part of daily business operations. Therefore, Proactive environmental strategy is going beyond compliance to a focus on prevention, a systemic approach that emphasizes source reduction and process innovation (Hart, 1995; Russo and Fouts, 1997).

These environmental management strategies have the link with pollution prevention (P2) hierarchy at different proportion and among them cleaner production concise perfectly with P2 concept (Phipps, 1995). 


\section{ENVIRONMENTAL MANAGEMENT STRATEGIES AND THEIR CASE STUDIES}

\subsection{Dilute and Disperse}

Passive waste management strategies were used by almost all industries in early 1900s and in some countries and industries these days as well. The philosophy behind it is that the environment provides inexhaustible resources and infinite absorption and dilution capacity for wastes. As a result, waste problems were avoided instead of fundamentally solved Kgabi and Mokgwetsi, 2009). In 1960s, dilute and disperse seemed to be adequate to make waste disappear in atmosphere and water ("the solution of pollution is dilution"). During the first 100 years of the Industrial Revolution, the volume of waste was relative small. A "dilute and disperse" waste disposal maxim prevailed. For example, industry and cities were purposely situated near rivers for a source of drinking water, supply water for industrial processes and cooling, provide an easy means for transportation of people and goods, and an easy avenue to remove the wastes dumped into them (Martin and Sutton, 2015).

This strategy fails in long run because hydrosphere and atmosphere is not a black box. Heavy metals, polychlorinated biphenyls(PCBs) and other diluted waste start to cycle and get accumulated in sediments or biomass, leading to contamination risks. In addition, enormous industrialization and urbanization results in large accumulation pollutant in the environment (Kgabi andMokgwetsi, 2009).

\section{Case Study One: Dilute and Disperse Strategy Implementation in United Kingdom}

Problem Description: Radioactive waste is a material deemed no longer useful that has been contaminated by or contains radionuclides. It has been created by military weapons production and testing; mining; electrical power generation; medical diagnosis and treatment; consumer product development, manufacturing, and treatment; biological and chemical research; and other industrial uses (Khan et al., 2010). With respect to radioactive substance dilute and disperse means discharging waste to the environment in such a way that environmental conditions and processes ensure that the concentrations of the radionuclides are reduced to such levels that the radiological impact of the released material is acceptable (IAEA, 2000). According to International Atomic Energy Agency (1995) report, dilute and disperse is a legitimate practice in the management of radioactive waste and has to be carried out within authorized limits established by the regulatory body.

In UK, Dilute and disperse used for the disposal of the majority of waste from unsealed radionuclides used in medicine and research (Martin and Sutton, 2015).In principle, this strategy experienced whereby low radioactive effluents can be discharged into the atmosphere or into the water resources, after appropriate control. Hazardous waste can be mixed with ordinary refuse, the absorptive power of which serves to retain dilute and gradually decompose or neutralize the waste. According to this view certain amount of acids, bases, sludge, tars, cyanide or heavy metals may be co-disposed with household refuse, without harming the environment (Nath and Hens, 1999). In actual practice, the situation may worse because the environmental components including human being will be affected. According to Nath and Hens (1999), United Kingdom is the only proponent for this strategy. The UK has accumulated around $4.5 \mathrm{~m}$ cubic metres of nuclear waste - enough to fill Wembley stadium four times over - since the development of nuclear facilities began after the Second World War. Created through electricity generation, defense operations and medical facilities such as radiography, most of this waste is currently stored at surface level in vaults and buildings on a site in Sellafield on the Cumbrian coast. To create a geological disposal site for the UK's radioactive waste, it estimated to cost $£ 12$ billion. The government-owned company asked to deliver a geological disposal unit. But still the implementation of the plan is under question (the guardian, 2015).

Another example is Brofiscin Quarry. It is the most polluted place in the United Kingdom.It wasused for about seven years for dumping of toxic waste including PCBs and was capped in 2011. It accepted waste from British Petroleum, Veolia Environment S.A and Monsanto Company (Salmon, 2012). 2005 report by Environmental Agency Wales found that the quarry contained up to 75 toxic substances, including heavy metals, Agent Orange and PCBs. The remediation cost would be 1.5 million pounds (BBC, 2011).

Nowadays, United Kingdom policy put different rules and regulation to control dilute and disperses environmental management strategy. For example, The United Kingdom Low Level Radioactive Waste (LLW) policy expresses a preference to concentrate and contain radioactive wastes instead of dilute and disperse and Basic Safety Standard (BSS) draft (2011) report mentioned that deliberate 
dilution of radioactive residues, other than the mixing of materials that takes place in normal operation when radioactivity is not a consideration, shall not be permitted. But the above mentioned case studies clearly show that still this strategy is under implementation in different extent.

\section{Case Study Two: Dilute and Disperse Type of Landfill in Malaysia}

Problem Description: Waste containment as a waste management strategy is expensive to implement and is beyond the means of many third world countries. Dilute and disperse type landfill are the norm. In this type of landfill the attenuation capacity of the unsaturated zone is exploited in order to reduce the impact of any leachate on the ground water system (Klinck et al., 1995). But the actual practice in the ground may worsen.

Malaysia is a South East Asia country where landfill is important and where the standard of waste management needs to be improved. All type of wastes (e.g. municipal waste, industrial waste, construction waste) are disposed in landfills without being pre-treated. MunicipalSolidWaste (MSW) generation is projected to increase from $292 \mathrm{~kg} /$ capita in 2000 to $511 \mathrm{~kg} / \mathrm{capita}$ in 2025 (Lau, 2004). At present, landfilling is the main waste disposal method ( $80 \%$ usage) and it is still expected to account for $65 \%$ of waste in 2020. Most landfills in the country are in a bad condition (Latifah et al., 2009), landfill operated without proper protective measures, such as lining systems, leachate treatment and gas venting. Norkhadijah e al. (2013), reported that currently, this strategy widely practice in the country but the impact of this strategy may worse in near future and this strategy not acceptable so they recommend searching sustainable options.

\subsection{End-of-Pipe Approach}

From the 1960s onwards, it became obvious that the dilute and disperse strategy was no longer effective for important point-source pollutions. A complete technology and business was developed to install purification units at the end of the emission pipes of various production processes. This approach is called 'end-of-pipe' because they usually represent the last stage of a process before the stream is disposed or released to the environment. Although effective to a certain extent the end-ofpipe approach is not "the solution". It generally produces by-products like purification sludge, which have to be dumped or burned and consequently cause other environmental impacts. Furthermore, the system does not reduce the amount of waste production; it transfers pollution from one medium to another medium; it does not eliminate pollution entirely and had limitations to solve environmental problems in their whole complexity. Eco-efficient technologies for end of pipe waste treatments are also so expensive cannot anticipate changes in environmental issues in the future (Welford and Gouldson, 2002). Therefore end of pipe approach is not successful at all mainly for dispersed pollution sources (Nowosielski et al., 2007).

\section{Case study one: Waste Water Treatment in Sierra Nevada Brewery}

Problem Description: waste water is the main issue of most industrial activities. Ramalho (1983) says that the main sources of wastewater are domestic sewage, industrial wastewater, agricultural runoff, and urban runoff.Breweries are one of the industrial sources of waste water. For brewery wastewater, Goldhammer (1999) discusses the characteristics of this byproduct both physical and chemical. Physically, there is oil, grease, and TSS or a total suspended solid, which refers to any solid particle that may have been chemically created through the brewing process. Other components of brewery effluent (wastewater) include BOD (biochemical oxygen demand), phosphorus, and COD as emphasized by Vasso and Russ (2007). Therefore, this waste should be treated before it discharges to the environment.

It is obvious this strategy need initial investment but the cost can be compensated or obtains even a benefit from this treatment by improving the treating system and in payback period. We can observe this in Sierra Nevada Brewery case. As analyzed by Shah-Ganai (2011), Sierra Nevada Brewery Company implements waste water treatment and obtain substantial economic benefit from it as shown in the table below, the partial budgeting table for Sierra Nevada. As shown, the implementation of an anaerobic digester save the firm money on water costs and this money saved could be thought of as an addition to the company's income. Partial budgeting for this project (Sierra Nevada) only accounts for income changes and cost changes for first year. Without the digester being put in place, the brewery pays roughly $\$ 890,000$ as opposed to $\$ 468,703$. They are saving $\$ 421,296.20$ per year or $\$ 35,108.01$ 
a month; after payback is done all additional savings that are a result from anaerobic digester can be used in other divisions of the company. According to Diane Greer who wrote an article about implementing anaerobic digesters for various companies, the average payback period ends up being about seven years (Greer, 2007).

Table1. Cost and benefits of waste water treatment in Sierra Nevada Brewery Company

\begin{tabular}{|c|c|c|c|}
\hline Added Inco & lue to change: & Added cc & nge: \\
\hline Water costs & $\$ 421,296.20^{*}$ & Anaerobi & $\$ 142,857^{*}$ \\
\hline Reduced co & ue to change: & Reduced & changes: \\
\hline Water cost: & $\$ 349,305.00^{*}$ & None (ut & ance unattainable) \\
\hline Sewer cost: & $\$ 119,398.80^{*}$ & & \\
\hline & & Subtotal & $\$ 142,857$ \\
\hline & & $0-142$, & \\
\hline
\end{tabular}

To further show the reasoning for implementing this technology, a net present value (NPV) analysis and cost-benefit was done on Sierra Nevada. Below is the cost-benefit analysis as well as an NPV table.

Table2. Net Present Value obtained from waste water treatment

\begin{tabular}{|c|c|c|}
\hline Summary of Costs and Benefits: & \multicolumn{2}{|l|}{ Cost Description: } \\
\hline Costs of new proposed project: & & \\
\hline Equipment purchase: & \multicolumn{2}{|l|}{$(925,000.00)^{*}$} \\
\hline Installation: & \multicolumn{2}{|l|}{$(75,000.00)^{*}$} \\
\hline Increased revenue: & \multicolumn{2}{|l|}{$421,296.20$} \\
\hline Reduced water costs: & \multicolumn{2}{|l|}{$468,703.80$} \\
\hline Net Savings: & \multicolumn{2}{|l|}{$(110,000.00)$} \\
\hline NPV (for first 10 years) & \multicolumn{2}{|c|}{$\begin{array}{l}\text { Minimum acceptable return }=10 \% \text { for } 10 \text { years } \\
\text { Use } 6.144 \text { as annuity factor }\end{array}$} \\
\hline $\begin{array}{l}\text { Years } 1-10 \\
\$ 421,296.20\end{array}$ & $\begin{array}{l}421,296.20(6.144) \\
\text { Less initial investment } \\
\text { NPV }\end{array}$ & $\begin{array}{l}\$ 2,588,443.85 \\
\$ 1,000,000.00 \\
1,588,443.85\end{array}$ \\
\hline
\end{tabular}

\section{Case study two: Hazardous Waste Management in Nepal}

Problem Description: Nepal has many problems with medical waste which impact adversely the environment including human health. Health Care Foundation Nepal (HECAF) has been working on medical waste management since 1999. There is a national guideline on medical waste management, but it has not been implemented. As a result, many hospitals use small scale incinerators, or open burn or dump the waste in their premises until the garbage pickers comes and dispose in the landfill. Most of the incinerators have a problem of quality and maintenance of equipments. These issues are not given adequate attention (Kumar, 2012).

If properly implemented, Incinerator facilities not only reduce final disposal of waste, but also produce electricity and/or heat, saving (energy) resources elsewhere.However, incineration plants also contribute to externalities, such as emissions to air and chemical waste residuals (Dijkgraaf and Vollebergh, 2003). In the Nepal case, the situation is worsen because it is not properly build and around the burning equipment there are residences who could directly affected by emission of smoke.

\subsubsection{On - Site Recycling Approach}

End of pipe methods often resulted in increased costs with no appreciable benefits to industries in terms of enhanced materials or energy uses, as a result, recycling wastes and resource recovery methods were evolved in 1980s; which were actually better mechanisms of resource use and waste minimization tactics over the end-of pipe strategy (Staniškis, 2001; Nowosielski et al., 2007). Recycling the waste on-site by returning the waste back to the process or another process (e.g., the use of waste acids and bases for $\mathrm{pH}$ adjustment in waste water treatment systems or the use of a small Onsite still to purify degreasing solvents for subsequent reuse) (http://www.inece.org/ mmcourse/ sect6.pdf). 
Often, there are critics of recycling such as more energy usage and cost may be incurred in getting materials to the recycling facility than is saved from the recycled products. Other limitations include market demand and technical issues from the fact that happen from the fact that wastes are heterogeneous in nature. To recycle economically there has to be a demand for the recycled product (Cabral et al., 2013).

Whatever the case may be, recycling techniques in waste management strategy can provide multiple benefits provided that it is technically and economically feasible. Some of the benefits of recycling wastes include reducing the demand for raw materials by extending their life and maximizing their value; reducing ecological damage, pollution and waste generation associated with raw materials extraction and use; reducing transport costs and pollution from transporting raw materials; saving energy in the production process; reducing emission to air and water in the production process; reducing disposal impact (less waste goes to landfill and incinerators); creating employment opportunities and so on (Nowosielski et al., 2007). Thus, recycling not only helps to reduce the overall amount of waste sent for disposal, but also helps to conserve natural resources by replacing the need for virgin materials (World Bank, 1998)

\section{Case study one: Water Recycling in Textile Industries}

Problem Description: Textile industries need substantial amount of water especially Dyeing Process. Therefore, recycling of the used water after treatment is very important. The two most well-known companies in Environmental management strategy in UK recycles and reuse water on site and obtain substantial benefits. The first company is medical textile company in Lancashire, it recycles cooling and condenser water, saving almost $11000 \mathrm{~m}^{3}$ of borehole water. Savings on effluent disposal alone amount to $£ 3000$ /year. Water pumping, treatment and energy savings are also achieved by recycling this water. It also saves almost $7000 \mathrm{~m}^{3}$ of borehole water by recycling the last rinse water from beam-and-winch bleaching operations. This accounts for savings in effluent disposal of $£ 2700$. The other company is a Scottish cloth finisher and it saves approximately $£ 5000 /$ year by recycling cooling water from its solvent-scouring plant for use in wet processing. Apart from reducing water and effluent costs, recycling also achieves energy savings as a result of the pre-heated water and the reduced demand on borehole pumps (Dubey and KhushbooJain, 2015).

\section{Case study two: Recycling approach in Lockheed Martin Mission Systems and Training Company in New Jersey}

Problem Description: Many of the technologies we use every day consume a lot more resources and power than they need to, and using and manufacturing them can create a mess. This technology can harm the environment through Pollution, Consuming resources (Non- renewable resources and renewable resource), huge waste production, disrupting ecology and result in health hazards. Therefore, manufacturers energy-efficient and less hazardous electronics (http://www. Carnegiecyber academy.com/facultyPages/environment/issues.html)

Lockheed Martin Mission Systems and Training (MST) provide systems engineering, software development, complex program management, supply chain solutions and logistics, and training and simulation technologies for global security, civil and commercial markets (http://www. Lock heed martin.com/us/mst/about.html). This company has a recycling program to recycle paper, commingled bottles and cans and corrugated cardboard are separated and recycled inside the factory. Lockheed Martin also initiated a food waste composting program in the $2^{\text {nd }}$ quarter of 2011 (New Jersey WasteWise Business Network, 2013). This composting is also a part of recycling

Lockheed Martin's recycling data focuses on the avoided cost of disposal that it realized thanks to their recycling efforts. In 2011, the company realized $\$ 145,562.57$ in savings as a result of material being recycled rather than disposed, as follows:

Table3. Recycled materials and cost saved due to recycling MST Company

\begin{tabular}{|l|l|l|}
\hline Recycled Material & Quantity Recycled & Recycling Cost Savings \\
\hline Asphalt & 685.00 Tons & $\$ 60,204.65$ \\
\hline Comingled Bottles \& Cans & 24.19 Tons & $\$ 1,783.77$ \\
\hline Concrete & 673.00 Tons & $\$ 59,179.97$ \\
\hline
\end{tabular}




\begin{tabular}{|l|l|l|}
\hline \hline Electronic Scrap & 14.05 Tons & $\$ 1,235.12$ \\
\hline Metal & 94.44 Tons & $\$ 8,300.33$ \\
\hline Mixed Wood and Pallets & 89.07 Tons & $\$ 4,054.11$ \\
\hline Paper and Cardboard & 146.93 Tons & $\$ 10,834.62$ \\
\hline \multicolumn{2}{|l|}{ Total Cost Savings (Avoided Cost of Disposal) $=$} & $\$ 145,562.57$ \\
\hline
\end{tabular}

Environmental Benefits: are Greenhouse gas emission reduction from landfill namely methane and carbon dioxide will be reduced and Leachate production will be avoided which can affect the ground water system.Recycling reduces the need for raw materials such as metals, forests and oil and so reduces our impact on the environment.

Socialbenefits: It create more job opportunity to collect,sort and reprocess of recyclables. The health of the society will be kept because there is avoidance of bad smell and odour and pollution and help us to sustain our live.

\subsubsection{Cleaner Production}

After 1990s, new ideas have emerged to reduce emissions to the environment at the source i.e. proactive environmental strategy. It is a dynamic capability that allows organizations to evolve and align their strategy with the changing and uncertain environment.It has been argued that, the transition from reactive to proactive approaches involves complex organizational changes that do not always result in business success (Aragón-Correa and Rubio, 2007). This pollution prevention and waste minimization strategy appeared to be necessary to reduce the enormous costs of clean-up actions, certainly from the moment that the polluter pays principle was brought into legislation. This new approach of cleaner production seems very promising because it combines an environmental and a business concern. In 1989, the United Nations Environment Program (UNEP) first introduced the concept of Cleaner Production (CP). It definesCP as is a conceptual and procedural approach to production that demands that all phases of the life-cycle of a product should be addressed with the objective of prevention or minimization of short and long-term risks to humans and to the environment". The goal of cleaner production is to reduce the adverse impact of production and service activities on the environment. Cleaner Production Options includes housekeeping, process optimization, raw material substitution, new technology and new Product Design. The continuous application of an integrated preventive environmental strategy applied to processes, products, and services to increase overall efficiency and reduce risks to humans and the environment. CP create Win-Win-Win situation for environment, community and business (UNEP, no date).

\section{Case Study one: Cleaner Production Strategy in Dupont Chemical Industry}

Problem Description: The chemicals industry is one of the most complex manufacturing and production facilities that require significant high-end and fixed capital costs that contribute to the a high degree of rivalry. US chemical manufacturer, DuPont, is one of the largest and oldest global firms in the chemicals industry, maintaining operations in over 90 countries worldwide, with a recorded $\$ 36$ billion in revenues, Given its high profile position within its industry, DuPont has chosen to address corporate sustainability as a leader in the industry, developing proactive climatechange related strategies that have led to both a reduction in their environmental impact and an increase their competitive advantage (Hoffman, 2006). One of these strategies focused on the reduction and control of its hydrofluorocarbon (HFC) emissions (Calub, 2015).

Under the 1992 Kyoto Protocol (an international treaty on climate change) and 1988 Montreal Protocol an international treaty on ozone layer protection), many countries and firms were pressured to develop emission-reduction projects through regulation, financial incentives and voluntary commitments (Andersen et al.,2010). Part of this reduction effort includes an eventual phase out of HFC-23, an unwanted byproduct of hydrochloroflourocarbon-22 (HCFC-22). HFC-23 is a chemical that depletes the ozone layer and is a common refrigerant manufactured by DuPont (Hoffman, 2006).

There are three options to managing HFC-23 reduction: 1.) Stop production of HCFC-22 through development of substitute chemicals or leaving the market, 2.) Reduce amount of HFC-23 per unit of HCFC-22 (i.e. minimize the HFC-23/HCFC-22 output ratio), or 3.) Use "end-of-pipe" solutions that incinerate HFC-23 just before it's released into the environment (Andersen et al., 2010).

Hoffman (2006) highlights some of the strategic actions that DuPont took to increase its competitive advantage. First, DuPont set a strategic objective of reducing its Greenhouse Gas (GHG) emissions by 
$40 \%$ of 1990 levels by 2000 and $65 \%$ of 1990 levels by 2010, targeting GHG emissions that had great impact and were considered "low hanging fruit" such as HFC-23. Second, DuPont aggressively invested in all three options towards HFC-23 reduction, requiring significant research and development, innovation, and initial capital investment. Third, DuPont took a proactive approach in driving voluntary and regulatory recommendations towards HFC-23 through heavy involvement and partnerships with Non-Governmental Organizations (NGOs), regulatory agencies, and other market stakeholders. Based on Hoffman (2006), Table 4 highlights the results of DuPont's proactive environmental strategic actions in managing HFC-23, leading to an improved competitive advantage for the firm. The expectation by the Montreal Protocol is that, minus a few exceptions, production and consumption of all emissive uses of HCFC-22, and thus HFC-23, will be phased out by 2020 in all developed countries and 2030 in developing countries (Andersen et al., 2010).

Today, DuPont continues to remain proactive in its reduction efforts and focus on climate change. Actively engaged in ongoing update of the Montreal Protocol, DuPont has been continuously advocating for a HFCs cap and reduction plan that not only moves the industry towards alternative products with lower GWP but provides the firm with an even greater competitive advantage (DuPont, 2013). Accordingly, much can be learned from the progressive efforts of a global company such as DuPont. As firms continue to migrate towards CS initiatives and strategies, Environmental, Health and Safety (EHS) professionals must take a similar holistic approach and continue to develop Proactive Environmental Strategies (PES) that not reduce a firm's ecological impact but provides a competitive advantage. The "win-win" approach evaluates PES not only as an opportunity to improve the environmental performance but the economic performance of the firm, where reducing the firm's ecological footprint is equal to improving the firm's competitive advantage (Calub, 2015).

Table4. Proactive Environmental Strategies as a Competitive Advantage at DuPont

\begin{tabular}{|c|c|c|}
\hline Net Impact & Specific Actions & Results \\
\hline GHG Reduction & $\begin{array}{l}\text { - Establish and achieve long-term company } \\
\text { objective: Reduce GHG emissions } 40 \% \\
\text { below } 1990 \text { levels by year } 2000\end{array}$ & $\begin{array}{l}\text { - } 40 \text { billion lbs. reduction of GHG } \\
\text { - Met } 1994 \text { Reduction Target Goal by of by } 1999\end{array}$ \\
\hline $\begin{array}{l}\text { Risk and Crisis } \\
\text { Management }\end{array}$ & $\begin{array}{l}\text { - Reduce regulatory liability: First company } \\
\text { to participate in EPA Department of } \\
\text { Energy Climate Wise Program }\end{array}$ & $\begin{array}{l}\text { - Remain ahead of the curve on regulation } \\
\text { - Continuous pressure on regulators to develop stricter } \\
\text { regulatory requirements }\end{array}$ \\
\hline $\begin{array}{l}\text { Resource and } \\
\text { Operations } \\
\text { Optimization }\end{array}$ & $\begin{array}{l}\text { - Initial high-cost investment in TQM } \\
\text { optimization of production line } \\
\text { - Advanced incineration technologies using } \\
\text { thermal destruction }\end{array}$ & $\begin{array}{l}\text { - } \$ 2 \text { billion cost savings through energy reductions and } \\
\text { yield improvements between } 1990 \text { and } 2005\end{array}$ \\
\hline Brand Management & $\begin{array}{l}\text { - Promote Corporate Vision: "To be the } \\
\text { world's most dynamic science company, } \\
\text { creating sustainable solutions to a better, } \\
\text { safer and healthier life for people } \\
\text { everywhere." }\end{array}$ & $\begin{array}{l}\text { - Cited in Business Week magazine as "top company of the } \\
\text { decade" from 1995-2005 for its climate-change } \\
\text { achievements. } \\
\text { - Ceres, non-profit organization advocating sustainability } \\
\text { leadership, names DuPont leader in its industry in } 2005\end{array}$ \\
\hline $\begin{array}{l}\text { Industry Standards } \\
\text { Involvement }\end{array}$ & $\begin{array}{l}\text { - Remain active with Intergovernmental } \\
\text { Panel on Climate Change (IPCC), Pew } \\
\text { Center, Business Roundtable }\end{array}$ & $\begin{array}{l}\text { - Received early action credits for achieving voluntary } \\
\text { GHG reduction goals } \\
\text { - Continuous pressure on IPCC to develop stricter voluntary } \\
\text { guidelines regarding HFC-23/HCFC-22 ratio }\end{array}$ \\
\hline Radical Innovation & $\begin{array}{l}\text { - Research \& Development (R\&D) } \\
\text { investment towards patented production } \\
\text { line of HCFC-22 }\end{array}$ & $\begin{array}{l}\text { - Proprietary production line with a } 1.37 \% \text { HFC- } 23 / \mathrm{HCFC} \text { - } \\
22 \text { ratio output (vs. average } 2 \% \text { HFC-23/HCFC-22 by } \\
\text { most competitors) }\end{array}$ \\
\hline
\end{tabular}

Case study two: Cleaner production in NEEASAE Fluorescent Lamps Manufacturing Industry, Egypt

Problem Description: According to UNEP (2004), Neeasae is a public sector company, mainly producing fluorescent lamps in Egypt. The maximum yearly production capacity is about 11 million lamps from different types. Liquid mercury $(\mathrm{Hg})$ is used in the production process of fluorescent lamps. The production process includes flushing of mercury, removal of impurities, and then filling with an inert gas (e.g. Argon or other gases depending on type of lamp). The mercury flushing causes emissions into the work environment. A Mercury vapour concentration has reached $0.25 \mathrm{mg} / \mathrm{m} 3$, the maximum limit set by the Egyptian Environment law is $0.05 \mathrm{mg} / \mathrm{m} 3$. The total consumption of mercury was $76.92 \mathrm{~kg}$ per 1 million lamps and the estimated pollution load was $400 \mathrm{~kg}$ of hg per year. 
Cleaner production project implementation aimed at the protection of workers health by reducing the exposure to mercury vapour. This was achieved by adopting a leaner production solution consisting of replacing mercury flushing of lamps by flushing argon. But still Mercury is used in the lumps, about $15-20 \mathrm{mg}$. per lamp since it is an essential element in emitting light (this amount is dosed in complete insulted environment, assuring no contamination $t$ the working environment). The project succeeded in reducing the amount of mercury used per lamp from $76.92 \mathrm{~kg} / \mathrm{million}$ lamps to $20 \mathrm{~kg} / \mathrm{million}$ lamps.

The new project with investment cost (200,549 US dollars) was financed through Egyptian Pollution Abatement Programme (EPAP) by a soft Loan package from the World Bank (20\% grant $80 \%$ loan). The commissioning of the project was in September 2000; the company if following strictly the selfmonitoring plan agreed with EPAP and maintenance plans recommended by the supplier. EPAP has finalized post completion report for this company in December 2001.

Environmental Benefits: Current measurements in the work environment are shown in the following table, which compares the concentrations and loads of mercury before and after the implementation of the project.

Economic Benefits: A cost benefit analysis was conducted which proved that there is no monetary benefit associated with this project per se. However, there are reduced health care costs. Also the availability of argon locally is of great benefit since this implies savings in foreign currency required for importing mercury.

Currently, the company isInternational Organization for Standardization: ISO14001 and ISO9001 certified and become an exemplary company in the Egypt (http://neeasae.en.hisupplier.com/aboutus.html).

Table5. Pollutant concentration variation due to cleaner production project

\begin{tabular}{|l|l|l|l|l|}
\hline Pollutant & Before Project & After Project & Tech. agreement & $\begin{array}{l}\text { Environmental } \\
\text { Legislation }\end{array}$ \\
\hline Mercury emissions & $0.25 \mathrm{mg} / \mathrm{m}^{3}$ & $0.01 \mathrm{mg} / \mathrm{m}^{3}$ & $<0.05 \mathrm{mg} / \mathrm{m}^{3}$ & $0.05 \mathrm{mg} / \mathrm{m}^{3}$ \\
\hline Mercury load & About $0.4 \mathrm{t} /$ year & About $0.016 \mathrm{t} /$ year & About $0.04 \mathrm{t} /$ year & \\
\hline $\begin{array}{l}\text { Amount of mercury } \\
\text { used per 106 lamp }\end{array}$ & $76.92 \mathrm{~kg} / 10^{6} / \mathrm{lamp}$ & $\begin{array}{l}20 \mathrm{~kg} / 10^{6} \mathrm{lamp} \\
\mathrm{kg} / 10^{6} \mathrm{lamp}\end{array}$ & $23.08 \mathrm{~kg} / 10^{6} \mathrm{lamp}$ & \\
\hline
\end{tabular}

3. The Link of Environmental Management Strategy with Pollution Prevention Hierarchy

Pollution prevention (P2) is the reduction or elimination of wastes and pollutants at their sources. For all the pollution that is avoided in the first place, there is that much less pollution to manage, treat, dispose of, or clean up.

The Pollution Prevention Act of 1990 explains clearly the hierarchy as follow:

i. Prevention: it is the most desirable option of the hierarchy and the most effective way to reduce risk. Pollution should be prevented or reduced at the source whenever feasible.

ii. Recycling: pollution that cannot be prevented should be recycled in an environmentally safe manner whenever feasible.

iii. Treatment: pollution that cannot be prevented or recycled should be treated in an environmentally safe manner whenever feasible; and

iv. Disposal: disposal or other release into the environment should be employed only as a last resort and should be conducted in an environmentally safe manner (Henry, 1992).

This hierarchy of preferred options for dealing with environmental pollution officially places prevention at the top of the list and disposal at the bottom (Phipps, 1995). 


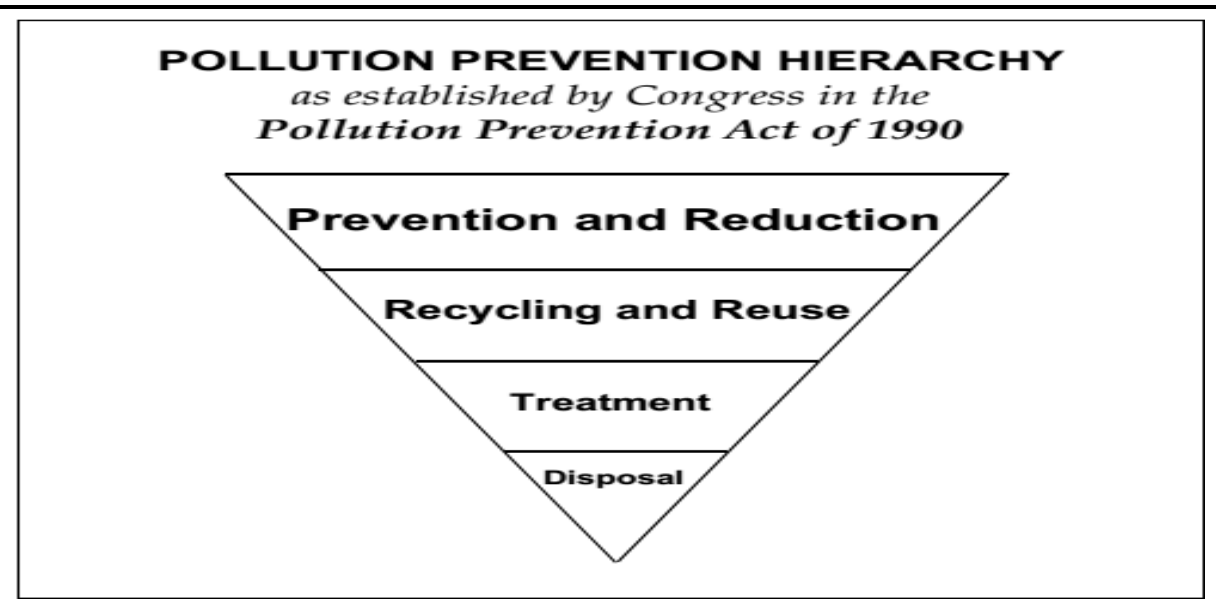

Figure1. Pollution prevention hierarchy (source: Phipps, 1995)

The concept of cleaner production mainly involves in pollution prevention strategy (Lei et al.,no date). Therefore, all waste prevention hierarchy could be implemented in CP. Even disposal option may be present in CP since there might be wastes that could not prevented, recycled and treated, thus the last option would be disposal in safe manner. According to UNEP (1998), there is one primary difference between P2andCP. While P2 is an environmental management concept Whichcan be applied to all sectors, CP is a technique designed morespecifically for sectors dealing with production processes, like the manufacturing sector. Therefore, CPrefersto P2 within the production process. Instead, $\mathrm{P} 2$ and $\mathrm{CP}$ programs attempt to reduceand/oreliminate air, water, and land pollution. Thus, both approach i.e. P2 and CP strongly linked with concepts and arepractical and feasible, and can consequently contribute to asustainable future (UNEP, 1998).

When we come to onsite-recycling environmental strategy it definitely related to the second hierarchy of pollution prevention from the top as shown in figure 1 above. It involves collecting, processing, and reusing materials that would otherwise be dumped as wastes (e.g., recycling spent solvents). On-site recycling of wastes provide considerable amount of resource recovery and cost reduction (http://www.inece.org/mmcourse/sect6.pdf).

The other strategy of environmental management tool is end of pipe approach and it linked with treatment option of waste prevention. But their basic assumptions are varied, in P2 treatment option become priority if the particular waste could not prevented and recycled (e.g., adsorption of organic vapors onto activated carbon) (Phipps, 1995). But in end of pipe the waste is produced without any hesitation and treated after the production and try to mitigate the negative consequences of production. Moreover, the wastes may be changed into other state not permanently treated for example solid waste may be burned at the end of a particular production but the smock may become another polluter. Furthermore, in P2 the waste generated and transferred to treatment option become few but in case of end of pipe the waste generation is very high. End-of- pipe solutions also focus on waste disposal as reported by (UNEP, 2003). Therefore, we can relate this strategy also with disposal because there are the cases where after disposal the wastes are treated.

The last and the very old approach is dilute and disperse environmental management tool. It related with the last option of P2 i.e. disposal. Here also the initial prioritization of this option for P2 and dilute and disperse is totally different. In case of P2, as already mentioned, it is the last option and either only few wastes reach there(e.g., landfilling metal scrap wastes) or totally no waste on that hierarchy. But in case of Dilute and disperse, it is the prime option and widely practiced.

\section{Conclusion}

Theoretically, there is evolution of environmental management starting from older strategy of ignoring the problems to newer proactive measure but in practice the evolution is disrupted and every environmental management strategy found in different countries currently as witnessed from different case studies. Therefore, there should be strong enforcement of established policies to clean the environment and to move forward towards cleaner production which is sustainable practice. The environmental management strategies (passive, reactive and proactive) have a linkage with pollution prevention hierarchy at different level. 


\section{REFERENCES}

Andersen, Stephen O, K MadhavaSarma, and David Doniger. 2010. "Making Climate Change and Ozone Treaties Work Together to Curb HFC-23 and Other 'Super Greenhouse Gases ." New York. www.nrdc.org/policy.

British Broadcasting Corporation (BBC). 2011 Brofiscin Quarry pollution at Groesfaen to be cleaned.BBC 15 June.

Cabral M, Ferreira S, Simoes P, da Cruz NF, Marques RC (2013). Financial flow in the recycling of packaging waste: The Case of France. Pol. J. Environ. Stud. 22(6):1637-1647.

Calub, M.E. 2015. Proactive Environmental Strategies: Managing aCorporate Culture Shift toward Sustainability. Theses, Dissertations and Projects.University of San Francisco.

Dijkgraaf, E and Vollebergh, R.J. 2003. Burn or Bury?A Social Cost Comparison of Final Waste Disposal Methods. SIEV - Sustainability Indicators and Environmental Valuation.NOTA DI LAVORO 46.2003.

Dubey, B and KhushbooJain. 2015. Recycling Of Textile Waste Is The Best Way To Protect Environment. IOSR Journal of Environmental Science, Toxicology and Food Technology (IOSR-JESTFT).e-ISSN: 2319-2402,p- ISSN: 2319-2399. Volume 1, Issue 1, PP 37-43 www.iosrjournals.org

Henry, F.H.II. 1992. Memorandum: EPA Definition of Pollution Prevention. U.S. Environmental Protection Agency.

Hilson, G. 2000a. An Examination of Environmental Performance and Eco-Effaciency in the North American Gold Mining Industry. MA thesis.University of Toronto.

Hilson, G. 2000b.Barriers to implementing cleaner technologies and cleaner production (CP) practices in the mining industry: A case study of the Americas. Miner Eng 2000;13 (7):699 -717.

Hilson G. 2003. Defining "cleaner production" and "pollution prevention" in the mining context. Miner Eng;16:305-21. http://repository .usfca. edu/capstone.

Hoffman, A. J. 2006. "Getting Ahead of the Curve: Corporate Strategies That Address Climate Change.” SSRN Electronic Journal. Arlington.doi:10.2139/ssrn.1635790.

IAEA. 2000. Predisposal Managementof Radioactive Waste, Including Decommissioning. IAEA, Safety Standards Series No WS-R-2, IAEA,Vienna.

International Atomic Energy Agency (IAEA). 1995. The Principles of Radioactive Waste Management, Safety Series No. 111-F, IAEA, Vienna.

Khan, S., Syed, A., Ahmad, R., Rather, T. A., Ajaz, M., \& Jan, F. 2010. Radioactive Waste Management in A Hospital. International Journal of Health Sciences, 4(1), 39-46.

Klinck, B.A., Crawford, M.C. and Noy, D.J. 1995.A Groundwater Hazards Assessment Scheme for Solid Waste Disposal.Natural Environment Research Council. International Division,British Geological Survey. Keyworth,Nothingham.United Kingdom, NG12SGG.

Kumar, D. 2012. Mapping Needs and Activities on Waste Management, Nepal. Asia Pacific Workshop on Global Partnership on Waste Management and Integrated Solid Waste Management

Latifah, A.M., MohdArmi A.B., Nurllyana, M.Z. 2009. Municipal solid waste management in Malaysia: Practices and challenges. Waste Manage. 29:2902-2906.

Lau, V.L. 2004. Case Study on the Management of Waste Materials in Malaysia. Forum Geookol.15(2).

Martin, C.J. and Sutton, D.G. 2015.Practical radiation protection in Health care. $2^{\text {nd }}$ edition, Oxford University Press.

Nath, B and Hens, L. 1999. Environmental management in practice.Compartments, stressors and sectors.Vol. 2, pp.30.UNSCO.

New Jersey WasteWise Business Network . 2013. The Economic Benefits of Recycling and Waste Reduction - WasteWise Case Studies from the Private and Public Sectors. Preserving resources, preventing waste. 
Norkhadijah,S., Ismail, S.andAbd. Manaf, L. 2013. The challenge of future landfill: A case study of Malaysia. Journal of Toxicology and Environmental Health Sciences.Vol 5(6), pp 86-96. DOI 10.5897/JTEHS12.058.I SSN 1996-0816 (C) 2013 Academic Journals http://www.Academic journals.org/JTEHS.

Nowosielski R, Bbilas R, Pilarczyk W (2007). Sustainable technology as a basis of Cleaner Production. Journal of Achievements in Materials and Manufacturing Engineering. 20 (1-2): 527-530.

Phipps, E. 1995.Pollution Prevention concepts and principles.Introductory Pollution Prevention Materials. National Pollution Prevention Center for Higher Education.

Salmon, B. LLP. 2012. Changes to the contaminated land regime. 12 April 2012.

Staniškis J (2001). Environmental Management: Strategies and Implementation. Environmental Research, Engineering and Management. 2(16): 3-10.

the guardian, 2015. Retrieved from https://www.theguardian.com/environment/2015/aug/17/ukradioactive-waste-disposal-site-search-continues-opposition.retrieved on June, 2016.

United Nations Environment Programme (UNEP). 1998. Principles of Pollution Prevention and Cleaner Production. An International Training Course.People's Republic of China Version.

UNEP. 2003. Urban Waste Management Strategy. The UNEP-International Environment Technology Centre (IETC). Division of Technology, Industry and Economics.

UNEP. 2004. voluntary environmental initiatives for sustainable industrial development concepts and applications. Division of Regional Cooperation Regional Office for West Asia (ROWA).united nations publication. ISBN number: 92-807-2480-0.

UNEP, no date.Basics of Cleaner Production.Division of Technology Industry and Economy.Swedish International Development Agency.Session two power point presentation.

World Bank (1998). Pollution prevention and abatement handbook section 2. Implementing policies in practice: industrial management, implementing Cleaner Production. The World Bank. Herndon, USA. 